\title{
The Complex Relationship of Extracorporeal Membrane Oxygenation and Acute Kidney Injury: Causation or Association?
}

\author{
Daniel J. Kilburn, ${ }^{1,2,3}$ Kiran Shekar, ${ }^{1,2}$ and John F. Fraser ${ }^{1,2}$ \\ ${ }^{1}$ Critical Care Research Group, The Prince Charles Hospital, 627 Rode Road, Chermside, Brisbane, QLD 4032, Australia \\ ${ }^{2}$ School of Medicine, The University of Queensland, Brisbane, Australia \\ ${ }^{3}$ Royal Brisbane and Women's Hospital, Brisbane, Australia
}

Correspondence should be addressed to John F. Fraser; john_fraser@health.qld.gov.au

Received 27 September 2015; Revised 29 January 2016; Accepted 31 January 2016

Academic Editor: Maciej Banach

\begin{abstract}
Copyright (C) 2016 Daniel J. Kilburn et al. This is an open access article distributed under the Creative Commons Attribution License, which permits unrestricted use, distribution, and reproduction in any medium, provided the original work is properly cited.

Extracorporeal membrane oxygenation (ECMO) is a modified cardiopulmonary bypass (CPB) circuit capable of providing prolonged cardiorespiratory support. Recent advancement in ECMO technology has resulted in increased utilisation and clinical application. It can be used as a bridge-to-recovery, bridge-to-bridge, bridge-to-transplant, or bridge-to-decision. ECMO can restitute physiology in critically ill patients, which may minimise the risk of progressive multiorgan dysfunction. Alternatively, iatrogenic complications of ECMO clearly contribute to worse outcomes. These factors affect the risk : benefit ratio of ECMO which ultimately influence commencement/timing of ECMO. The complex interplay of pre-ECMO, ECMO, and post-ECMO pathophysiological processes are responsible for the substantial increased incidence of ECMO-associated acute kidney injury (EAKI). The development of EAKI significantly contributes to morbidity and mortality; however, there is a lack of evidence defining a potential benefit or causative link between ECMO and AKI. This area warrants investigation as further research will delineate the mechanisms involved and subsequent strategies to minimise the risk of EAKI. This review summarizes the current literature of ECMO and AKI, considers the possible benefits and risks of ECMO on renal function, outlines the related pathophysiology, highlights relevant investigative tools, and ultimately suggests an approach for future research into this under investigated area of critical care.
\end{abstract}

\section{Introduction}

Extracorporeal membrane oxygenation (ECMO) is being increasingly used in patients with cardiorespiratory failure whilst even more novel applications continue to evolve. ECMO may reduce mortality in patients with cardiopulmonary failure of multiple aetiologies, although conclusive evidence is still lacking [1-5]. ECMO is not a definitive treatment; it is a temporary support system that allows organ support whilst potentially disease-modifying therapy is administered or more definitive therapies are planned [6]. The institution of salvage ECMO is often reserved for patients with a predicted mortality rate in excess of $80 \%$ [7]. Improvements in clinical application and device design with a more precise appreciation of the patient-device interface, particularly with regard to haematological changes, have improved the risk : benefit ratio of ECMO [8-10].
An increase in the scope of indications has led to the implementation of ECMO in numerous critical care settings. These include the emergency department, specialized interhospital retrieval services, cardiac catheterisation lab, and during perioperative cardiac surgical management [8]. Despite this, mortality rates range from $40 \%$ to $60 \%$ in the adult population $[4-6,9,11,12]$. Initiation of ECMO can lead to restitution of physiology which may prevent the progression of preexisting disease or minimise harm caused by salvage therapy (i.e., frusemide infusion and/or inotropic support). Despite this, morbidity and mortality are predominantly caused by progression of preexisting disease; however iatrogenic factors contribute significantly. Thrombosis and haemorrhage are the most common serious iatrogenic complications, which result from a complex systemic response initiated by blood-surface interaction and a subsequent use of unfractionated heparin $[13,14]$. 

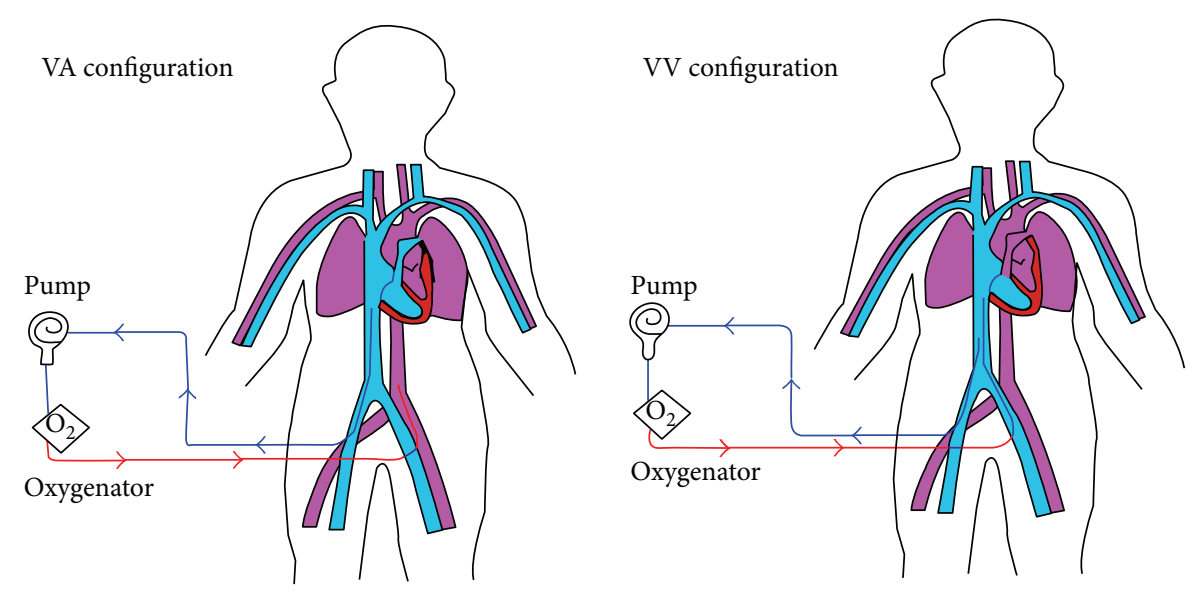

FIGURE 1: The various cannulation configurations used for ECMO. In both configurations, deoxygenated blood (blue line) is removed from the venous circulation. In venoarterial (VA) ECMO, oxygenated blood (red line) is returned to arterial circulation. Conversely, in venovenous (VV) ECMO the return is made to the venous system (reproduced with permission from Elsevier).

Equally, acute kidney injury (AKI) is also common in patients on ECMO, with incidence as high as $70 \%-85 \%$ $[7,15]$. AKI in conjunction with ECMO is associated with increased mortality rates of up to $80 \%[4,5,11,16-19]$. AKI is present both before and after initiation of ECMO; however clarity in regard to the timing and risk factors for major renal insult is lacking. Pharmacological therapy directed at preventing ECMO initiation is often implemented at the expense of kidney function and it is unclear whether the commencement of ECMO protects or exacerbates this. Despite the extensive literature investigating $\mathrm{AKI}$ in the setting of cardiopulmonary bypass (CPB), there are insufficient mechanistic and clinical data defining the link between ECMO and AKI [20]. A comprehensive understanding of this relationship and subsequent investigation of ECMOassociated AKI (EAKI) would enable clinicians to predict, treat, and ameliorate the clinical sequelae.

\section{ECMO Technique and Perfusion Strategies}

ECMO can be implemented as a venoarterial (VA) or venovenous (VV) configuration, determined by the clinical context (Figure 1) $[8,13]$. Peripheral and central VA ECMO is reserved for patients with inadequate cardiac function and may result in a pulseless circulation, especially when there is minimal native cardiac output [1]. VV ECMO is used for patients with isolated refractory respiratory failure and does not provide direct circulatory support [8]. These fundamental differences between VA and VV ECMO may have significant implications on the development of EAKI. A comprehensive review of the different types of ECMO cannulation is beyond the scope of this paper but is addressed in other journals $[1,8]$.

\section{ECMO-Associated Kidney Injury: Can Traditional Definitions Be Applied?}

AKI is characterized by an abrupt loss in renal excretory function leading to the retention of nitrogenous waste products and dysregulation of extracellular volume and electrolytes [21]. The incidence of AKI in critically ill patients is increasing, complicating the clinical course of almost $60 \%$ of patients admitted to intensive care units (ICU) [22, 23]. Due to the complexity of diagnosis, various unstandardized definitions and diagnostic criteria have existed and are still present throughout the literature [24]. This has hindered the advancement of research on AKI due to confounding comparisons among studies $[25,26]$. Because of this, bias in the literature examining diagnosis, incidence, and attributable mortality of AKI exists [27].

Recently, consensus on the definition of AKI by the Acute Dialysis Quality Initiative has been achieved [24]. The original RIFLE (risk, injury, failure, loss, and end stage) criteria and the revised Acute Kidney Injury Network (AKIN) criteria are now commonly used and well established throughout the literature $[28,29]$. Furthermore, these definitions have been consolidated into the KDIGO Clinical Practice Guidelines for AKI Definition [24, 30]. RIFLE and AKIN have been validated in various population settings, including patients on ECMO [20, 21, 31-35].

Despite subtle differences between RIFLE and AKIN (Table 1), it is not clear whether one is superior to the other, particularly in those supported by an ECC [24, 25, $29,31,36]$. Both have high sensitivity and specificity for diagnosing AKI [24, 25, 29, 31, 36, 37]. Furthermore, they correlate with clinical outcomes including length of hospital stay, requirement for renal replacement therapy (RRT), and overall mortality $[29,33,38]$. For ECMO, these criteria have good short-term prognostic capability and an independent mortality relationship exists for class-failure (RIFLE) and stage 3 (AKIN) (Table 2) [16, 31]. Despite this, research into the utility of RIFLE and AKIN criteria during ECMO and for the recognition of EAKI is limited and needs further investigation.

Neither RIFLE nor AKIN is perfect and a number of recognized limitations exist which may affect their efficacy in ECMO. Both utilise surrogate and delayed markers of renal impairment (i.e., serum creatinine and urine output) 
TABLE 1: The AKIN and RIFLE criteria for identification and staging of AKI.

\begin{tabular}{|c|c|c|c|c|c|}
\hline \multicolumn{3}{|c|}{ AKIN criteria* } & \multicolumn{3}{|c|}{ 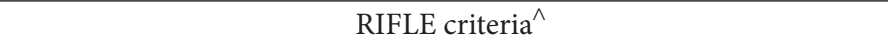 } \\
\hline Stage & Creatinine & Urine output & Stage & Creatinine or GFR & Urine output \\
\hline 1 & $\begin{array}{c}\text { Increase of } \\
>0.3 \mathrm{mg} / \mathrm{dL} \text { or } 0.5-2 \\
\text { times (baseline) }\end{array}$ & $\begin{array}{l}<0.5 \mathrm{mg} / \mathrm{kg} / \mathrm{hr} \\
\quad \text { for }>6 \mathrm{hr}\end{array}$ & Risk & $\begin{array}{c}\text { sCr increase } \times 1.5 \\
\text { (baseline) or GFR } \\
\text { decrease }>25 \%\end{array}$ & $<0.5 \mathrm{mg} / \mathrm{kg} / \mathrm{hr}$ for $>6 \mathrm{hr}$ \\
\hline 2 & 2-3 times (baseline) & $\begin{array}{l}\text { Anuria for } \\
12 \mathrm{hr} \text { or } \\
<0.5 \mathrm{mg} / \mathrm{kg} / \mathrm{hr} \\
\text { for }>12 \mathrm{hr}\end{array}$ & Injury & $\begin{array}{c}\text { sCr increase } \times 2.0 \\
\text { (baseline) or GFR } \\
\text { decrease }>50 \%\end{array}$ & $<0.5 \mathrm{mg} / \mathrm{kg} / \mathrm{hr}$ for $12 \mathrm{hr}$ \\
\hline \multirow[t]{3}{*}{3} & $\begin{array}{c}\text { RRT or level of } \\
4.0 \mathrm{mg} / \mathrm{dL} \text { with an } \\
\text { acute increase of } \\
0.5 \mathrm{mg} / \mathrm{dL}\end{array}$ & $\begin{array}{l}<0.3 \mathrm{mg} / \mathrm{kg} / \mathrm{hr} \\
\quad \text { for } 24 \mathrm{hr}\end{array}$ & Failure & $\begin{array}{c}\text { sCr increase } \times 3.0 \\
\text { (baseline) or GFR } \\
\text { decrease }>75 \% \text { or } \\
4.0 \mathrm{mg} / \mathrm{dL} \text { with an } \\
\text { acute increase of } \\
0.5 \mathrm{mg} / \mathrm{dL}\end{array}$ & $<0.5 \mathrm{mg} / \mathrm{kg} / \mathrm{hr}$ for $12 \mathrm{hr}$ \\
\hline & & & Loss & \multicolumn{2}{|c|}{ Persistent AKI (loss of renal function $>4$ weeks) } \\
\hline & & & ESKD & \multicolumn{2}{|c|}{ End stage kidney disease $>3$ months } \\
\hline
\end{tabular}

${ }^{*}$ Renal assessment time window up to 48 hours.

$\wedge$ Renal assessment time window up to 7 days.

TABLE 2: Kidney injury-specific independent predictors of mortality during various stages of ECMO treatment.

\begin{tabular}{|c|c|c|c|c|c|c|}
\hline Author & Journal & Year & Period & $\begin{array}{l}\text { Number of } \\
\text { patients }\end{array}$ & Relation to ECMO & $\begin{array}{l}\text { AKI-specific independent } \\
\text { predictors }\end{array}$ \\
\hline Lin et al. [11] & Ann Thorac Surg & 2007 & $2002-2005$ & 78 & On ECMO & RIFLE \\
\hline Yan et al. [31] & Euro J Cardiothoracic Surg & 2010 & 2004-2008 & 67 & On ECMO & $\begin{array}{c}\text { Class failure (RIFLE), } \\
\text { stage } 3(\mathrm{AKIN})\end{array}$ \\
\hline Chen et al. [18] & Ann Thorac Surg & 2011 & $2002-2008$ & 102 & $\begin{array}{c}\text { Post-ECMO (48 } \\
\text { hours) }\end{array}$ & AKIN (48 hours) \\
\hline Chang et al. [123] & PLoS One & 2012 & 2006-2010 & 119 & Post-ECMO & $\begin{array}{l}\text { Day } 2 \text { urine output after } \\
\text { ECMO }\end{array}$ \\
\hline Hsiao et al. [16] & Ann Thorac Surg & 2014 & $2006-2011$ & 81 & $\begin{array}{l}\text { Concomitant } \\
\text { ARDS }\end{array}$ & Urine output \\
\hline
\end{tabular}

to diagnose and stage AKI. Serum creatinine (sCr) is an insensitive and unreliable biomarker for early detection of kidney injury and recovery [39]. Changes in sCr only occur with a $>50 \%$ decline in glomerular filtration rate (GFR) and, along with urine output, can be influenced by a number of factors unrelated to renal dysfunction [39]. Early and accurate detection is important as "transient AKI" (the resolution of AKI within 72 hours of onset) is common and correlates independently with increased mortality [40]. In view of these limitations, future refinements should consider markers that are more sensitive and specific to the overall accuracy of diagnosis and early detection of renal impairment in patients on ECMO. Identifying the pathophysiological factors and physiological mechanisms that occur to the kidney in the context of ECMO may improve the accuracy and speed of diagnosis of EAKI.

\section{Pathophysiology of ECMO-Associated Kidney Injury}

It is clear that the pathophysiological features of EAKI are complex, multifactorial, and time dependant and likely to be synergistic. There is limited literature assessing the pathophysiological mechanisms of AKI and ECMO; however there is research that describes CPB-associated AKI. CPB produces a predominantly pulseless system, VA ECMO typically has limited pulsatility, and VV ECMO is always pulsatile. However, due to other similarities between $\mathrm{CPB}$ and ECMO, it is likely that there are at least some common underlying factors with VV and VA ECMO. Progression of preexisting multisystemic disease, pre-ECMO management, activation of proinflammatory mediators, alterations in renal macro/microvasculature, ischaemia-reperfusion, haemolysis and oxidative stress, disruption of the glycocalyx, impaired renal autoregulation, iatrogenic nephrotoxicity (i.e., antibiotics), and iatrogenic coagulation abnormalities are possible factors involved in the pathogenesis of EAKI [41]. These processes occur within the pre-ECMO, ECMO, and postECMO setting and may be prevented or exacerbated by ECMO initiation. Regardless, they are fundamental features leading to increased rates of AKI in the presence of an ECC $[42,43]$. Ultimately, they may contribute to the development of EAKI, a subset of type 1 and type 3 cardiorenal syndrome [44]. 
4.1. Systemic Inflammatory Response. Activation of proinflammatory mediators caused by the underlying disease process, combined with the interaction of blood on the nonendothelialised ECMO interface, may initiate and amplify a systemic inflammatory response. Proinflammatory cytokines such as interleukin-1 (IL-1), IL-6, IL-8, and tumour necrosis factor-alpha (TNF- $\alpha$ ) are believed to be the main contributors to this process $[42,43]$. These cytokines are released from activated leukocytes in the presence of endothelial cell injury and a nonphysiological extracorporeal surface, which should represent a coordinated systemic response in patients on ECMO [40]. However, a pathologic dysregulated host response with a hyperinflammatory cytokine storm may induce alterations of the glycocalyx and microcirculatory dysfunction and induce aseptic renal inflammation and injury [40, 45-48]. This exaggerated inflammatory response may be due to an overactivation of toll-like receptors and thus an increase in the transcription of factors that regulate the expression of proinflammatory cytokines [49]. An early hyperimmune and a later immunosuppressive response leading to sepsis-associated AKI have been suggested in the literature, and relevant targeted therapies to induce renoprotection continue to emerge [41, 46, 50-53]. A timedependant immune response and subsequent approach to treatment may also be useful in EAKI; however this has not yet been investigated.

4.2. Renal Macro/Microcirculatory Dysfunction. A systemic inflammatory response may also cause alterations in regional macro- and microvascular blood flow and vasomotor tone, often leading to a hyperdynamic, vasodilated state while on ECMO [52]. Similar to sepsis, this clinical phenotype manifests with tachycardia, hypotension, and an elevated cardiac output. Although difficult to substantiate in humans, due to the invasiveness of renal blood flow (RBF) monitoring, an increase in RBF in patients with this clinical phenotype on ECMO has been postulated $[54,55]$. Animal models of sepsisassociated AKI have demonstrated renal hyperaemia with increased RBF and decreased renal vascular conductance (RVC) in the presence of a decreased GFR [54, 56, 57]. This suggests an innate dissociation between $\mathrm{RBF}$ and renal function and a possible flow/perfusion (F/Q) mismatch, highlighting the role of the renal microvasculature in the development of EAKI. Disproportionate dilatation of the efferent arteriole compared to the afferent arteriole may reduce glomerular filtration pressure, leading to a decrease in GFR. However, the presence of microcirculatory dysfunction with possible preglomerular arterial-venous (AV) or arteriolar-arteriolar (AA) renal oxygen shunting may also account for this [58-62].

Microcirculatory dysfunction is likely to play a central role in the pathogenesis of EAKI, through both direct and "organ cross talk" mechanisms $[47,63]$. In pathological and nonpathological states, the autoregulation of renal microvasculature is responsible for the delicate balance of oxygen supply versus demand at the mitochondrial level [47]. An inflammatory and hypoxia-induced renal microvascular autoregulatory dysfunction with endothelial glycocalyx degradation results in precapillary sphincter relaxation and endothelial cell dysfunction [47, 48, 64, 65]. This leads to a heterogeneously perfused renal parenchyma with arteriovenous shunting and maldistribution of regional corticalmedullary blood flow independent of renal artery flow [47, 64, 66-68]. In conjunction with this, widespread endothelial capillary leak, oxygen utilisation defects at the mitochondria, and hypoxia of nephrons occur which may ultimately result in EAKI [47, 64, 66-68].

4.3. Ischaemia-Reperfusion Injury, Haemolysis, and Oxidative Stress. In order to achieve systemic haemodynamic targets and preservation of cardiorespiratory function in both a pre-ECMO setting and a preload-dependant ECMO circuit, certain management strategies are implemented. Frequent use of intravenous (IV) fluid and diuretic therapy, high PEEP strategies (pre-ECMO), regular adjustments in inotrope/vasopressor administration, and variations in ECMO circuit pressures (post-ECMO initiation) commonly occur. In the pre-ECMO setting, these interventions are often prescribed at the expense of renal function as the clinician attempts to delay or prevent the initiation of ECMO. The subsequent delay in the commencement of ECMO with potentially harmful therapy may compound the rapid fluctuations in microvascular blood flow leading to reperfusion EAKI [7, 17, 69]. Alternatively, the restoration of RBF with initiation of ECMO may also contribute to reperfusion EAKI.

Reperfusion injury is likely to be a key pathogenic event in the microcirculatory dysfunction leading to EAKI. It occurs due to inflammatory and oxidative stress-mediated injury, with leukocyte activation and production of reactive oxygen/nitrogen species (RNOS), following restoration of circulation to previously hypoxic cells and subcellular structures [70-72]. Within this process, mitochondrial dysfunction contributes significantly to EAKI [73]. The production of ATP by mitochondria via oxidative phosphorylation drives sodium reabsorption in the kidney tubules [47]. In the setting of multifactorial renal insult, the kidney loses important intrinsic physiological defence mechanisms, which increase the vulnerability of nephrons to oxygen free radicals [74]. ATP production is impaired in the presence of significant oxidative stress due to an increase in mitochondrial protein uncoupling, causing disruption of the mitochondrial membrane potential by the release of hydrogen ions [75]. This process may ultimately contribute to oxidative stressmediated EAKI.

As mentioned, excess IV fluid therapy before and during ECMO is likely to aggravate this pathophysiological process. Fluid boluses cause recruitment of these hypoxicshunted renal microcirculatory units and resuscitation of the mitochondria. This "washes/flushes" the hypoxic and acidotic capillary detritus into the circulation, further disrupting oxidative phosphorylation [76]. This also overrides the systemic protective and compensatory vasoconstrictive mechanisms, resulting in maldistribution of oxygen supply [76]. Furthermore, the microcirculatory reperfusion that occurs is ineffective at promoting renal tissue oxygenation due to the poor oxygen carrying capacity of IV fluid [47, $76,77]$. It is clear that the additional inflammation induced by fluid bolus promotes oxidative and inflammatory damage, 
potentiating tissue demise, and ultimately contributes to EAKI $[46,52]$. Novel treatment strategies in humans and animal models of critical illness attempt to prevent and ameliorate microcirculation dysfunction; however none have been performed in ECMO models [50, 76, 78-80]. Also, in view of the negative effects that the conventional use of fluid therapy has on kidney function, future refinements that will be based on microcirculatory variables are currently being considered [76, 81]. At present, it is unclear whether timely initiation of ECMO compared to salvage ECMO and lowcircuit pressures compared to high-circuit pressures reduces the effect of reperfusion and oxidative stress-mediated EAKI.

Haemolysis and subhaemolytic damage (leading to erythrocyte deformability), induced by the shear stress of the ECMO circuit, is also likely to contribute to EAKI through oxidative/nitrosative stress [82-88]. Among other variables, the shear stress is likely to be directly related to circuit pressures. The compromise in renal function caused by ECMO-induced haemolysis increases overall mortality in patients on ECMO and this is accentuated by prolongation of the ECC $[82,83,89-92]$. Homeostasis of oxygen, nitric oxide, and RNOS is essential to maintain normal renal signaling, immunity/cellular defence, microvascular function, and cellular respiration [93]. Haemolysis during ECMO disrupts this homeostasis through the effects of elevated levels of free circulating erythrocyte constituents with a relative deficiency of haptoglobin and transferrin [82, 87]. Plasma-free haemoglobin ( $\mathrm{fHb}$ ) and free iron are the main contributors to this process, causing prooxidant/nitrosative damage to the kidney. $\mathrm{fHb}$ reacts with hydrogen peroxide and scavenges nitric oxide, which undergoes redox cycling to form toxic free radicals $[84,94,95]$. $\mathrm{fHb}$ also converts into methaemoglobin and subsequently precipitates within the renal tubules $[92,96,97]$. Poorly liganded free iron is nephrotoxic as it forms RNOS, such as hydroxyl radicals and superoxide anions, particularly in acidic environments such as the renal tubular urine [94, 98-102]. Additionally, the supraphysiological oxygen content produced by the ECMO circuit leads to the formation of these RNOS in the presence of haemolysis, via the production of superoxide [87, 103-105].

Ultimately, the homeostatic imbalance caused by ECMOinduced haemolysis causes oxidative/nitrosative mediated kidney injury by altering the microvasculature and destruction of the glycocalyx $[47,87,106]$. As mentioned, this promotes leucocyte adhesion, disruption of the endothelial barrier, and glomerular filtration dysfunction $[47,106]$. Furthermore, RNOS cause diffuse microcirculatory vasoconstriction, platelet aggregation, lipid peroxidation, and a loss of polarity in renal tubular cells $[47,84,94,95,102,107]$. The damage to important renal cellular and subcellular structures by reactive mediators impairs normal renal function and causes progression to EAKI $[47,106]$. The administration of intravenous haptoglobin has shown prophylactic and therapeutic benefits in reducing rates of AKI, highlighting the effect of haemolysis on renal function $[82,108-$ 111]. In animal models, iron chelation with deferoxamine administration is protective against pigment nephropathy $[96,112,113]$. Interventions aimed at reducing the effect of RNOS on kidneys with $\mathrm{N}$-acetylcysteine, iloprost, vitamin $\mathrm{C}$, and dexamethasone and inhibition of inducible NO are promising, predominantly in animal models [53, 114-120]. However, the results of these therapies in more rigorous RCT settings have been disappointing and the effects of these therapies in the setting of ECMO have not yet been investigated. Furthermore, the effect of ECMO circuit pressures on haemolysis is unknown and warrants thorough investigation.

4.4. Other. The nonendothelialised ECMO interface and destruction of the glycocalyx may, in isolation or in combination, lead to a hypercoagulable state, which results in the formation of microemboli and microthrombi within the renal vasculature, particularly with VA ECMO $[121,122]$. Improvements in ECMO device design (e.g., incorporation of a roller pump with less biocompatible noncoated membrane surfaces) have led to less thrombus formation and an enhanced ability of the circuit to remove larger emboli; however smaller thrombus and emboli still persist [121, 122]. The resultant ischaemia of the renal parenchyma may precipitate AKI while on ECMO and result in EAKI. Novel treatment strategies that prevent thrombosis partly by preserving glycocalyx integrity, such as soluble thrombomodulin (sTM) and activated protein $\mathrm{C}$, are being investigated in the setting of sepsis-associated AKI; however their efficacy in EAKI is unknown $[48,50]$.

Patients supported on VV ECMO with respiratory failure and receiving lung protective ventilation have often had prolonged hypercapnia. Despite correction by ECMO, this induces significantly altered haemodynamics and RBF [124]. This can lead to acidosis, hypoxia, poor pulmonary compliance, and pulmonary hypertension, which can progress to cor pulmonale, shock, and organ dysfunction. The primary disease process in conjunction with ongoing lung injury and altered haemodynamics induced by ventilation may further exacerbate organ injury and increase the risk of EAKI [125]. To this end, timely initiation of ECMO may mitigate pre-ECMO risk factors for organ dysfunction and EAKI. Alternatively, raised intrathoracic pressure secondary to high positive-end expiratory pressure (PEEP) on ECMO may induce renal hypoperfusion and impair the kidneys excretory function [126, 127]. However, high PEEP in conjunction "ultralow" tidal volumes may actually help to reduce the overall intrathoracic pressure and ameliorate the potential negative effects on kidney function.

As mentioned, the centrifugal ECMO pumps are preload dependant and deficient in the Frank-Starling mechanism; thus maintenance and bolus IV fluid administration are necessary to maintain adequate ECMO flow and minimise "suckdown," particularly in the immediate days following ECMO initiation [128]. However, a positive fluid balance on day 3 of ECMO correlates with higher mortality [128]. Conversely, the subsequent use of diuretic therapy in order to achieve neutral fluid balance, minimise extravascular lung water, and improve gas exchange and pulmonary compliance may also further exacerbate EAKI [129].

Despite the pulsatility differences between $\mathrm{VV}$ and VA ECMO, provided that ECMO circuit flow rates are in the range of premorbid cardiac output, there is a lack of evidence to suggest that a nonpulseless system increases the risk of EAKI. Initiation of peripheral VA ECMO can lead to 
TABLE 3: Potential methods for investigating EAKI.

\begin{tabular}{|c|c|}
\hline Physiological & Biochemical \\
\hline $\begin{array}{l}\text { Urine output (UO) } \\
\text { Blood pressure (BP), cardiac output (CO), and central venous } \\
\text { pressure (CVP) } \\
\text { Renal blood flow (RBF), renal vascular conductance (RVC) } \\
\text { Renal artery transit-time flow probes with oximetry } \\
\text { Urine oxygen tension }\end{array}$ & $\begin{array}{l}\text { Serum/urine creatinine (sCr, uCr), blood urea nitrogen (BUN), } \\
\text { and serum potassium (K+) } \\
\text { Fractional excretion of sodium/urea (FeNa/FeUrea) } \\
\text { Creatinine clearance (CC), RIFLE and AKIN } \\
\text { Red cell distribution width (RDW), bilirubin, haptoglobin, } \\
\text { hepcidin, and plasma/urine albumin } \\
\text { Cockcroft-Gault equation (eGFR), fluorescence-based measured } \\
\text { GFR (mGFR) assay, and FITC-sinistrin excretion }\end{array}$ \\
\hline Radiological & Histological \\
\hline $\begin{array}{l}\text { Renal ultrasound + Doppler } \\
\text { Contrast-enhanced ultrasound (CEU) } \\
\text { Near infrared spectroscopy (NIR) }\end{array}$ & $\begin{array}{l}\text { General-hematoxylin and eosin stain (H\&E) } \\
\text { Fibrosis/collagen-Masson's trichome } \\
\text { Protein-periodic acid-Schiff (PAS) reagent } \\
\text { Lipofuscin-Schmorl's stain, iron-Perl's stain, and other: deposits, } \\
\text { casts, and necrosis }\end{array}$ \\
\hline Immunohistochemistry/other & Novel biomarkers (serum/urine) \\
\hline $\begin{array}{l}\text { Neutrophils, macrophages-anti-CD68, } \\
\text { Myofibroblasts-anti- } \alpha \text {-smooth muscle actin (SMA) } \\
\text { Apoptosis quantification-cleaved caspase-3 } \\
\text { Nitric oxide synthase, pimonidazole, and Pd phosphorescence } \\
\text { Syndecan- } 1 \text {, endocan, and selectin } \\
\text { Transmission electron microscopy with ruthenium red, ferritin, } \\
\text { lanthanum, and cupromeronic blue stain }\end{array}$ & $\begin{array}{l}\text { Neutrophil gelatinase-associated lipocalin (NGAL), } \\
\text { Cystatin C (CystC), kidney injury molecule (KIM-1), IL-6, and } \\
\text { IL-18 } \\
\text { N-acetyl-glucosaminidase (NAG), renal-liver type fatty acid } \\
\text { binding protein (L-FABP) } \\
\text { Insulin-like growth factor-binding protein } 7 \text { (IGFBP7), and tissue } \\
\text { inhibitor of metalloproteinases-2 (TIMP-2) } \\
\text { Syndecan-1, endocan, and selectin } \\
\mathrm{F}_{2} \text {-isoprostanes and isofurans }\end{array}$ \\
\hline
\end{tabular}

profound reperfusion and hyperaemia, which may exacerbate ischaemia-reperfusion injury. On the contrary, among other mechanisms, overall renal perfusion may improve as a result of the reduced venous pressure induced by the negative drainage pressure in the IVC.

An increased duration of support with ECC is an independent risk factor causing an increased incidence of AKI and subsequently higher morbidity and mortality [130]. This highlights the likelihood of an AKI that is induced by an extracorporeal circuit. As a result of the extended duration of therapy and the presence of significant acute and preexisting underlying disease of patients on ECMO, these factors are likely to cause greater consequences. This may be reflected by the high incidence of AKI with ECMO. On the other hand, management strategies that are implemented to prevent or delay initiation of ECMO in a critically ill patient may also be the predominant factor leading to high rates of EAKI. EAKI is not yet established within the literature, warranting further consideration and subsequent investigation into the "causation versus association" relationship to determine whether ECMO is a "friend or foe" to renal function.

\section{Methods for Investigating ECMO-Associated Kidney Injury}

A number of tools can detect and define the consequences that the various pathophysiological processes associated with EAKI have on renal function. Methods for determining AKI can be categorised into broad groups: physiological, biochemical, radiological, histological/immunohistochemical, and biomarker evaluation (Table 3 ).
5.1. Physiological and Biochemical. In current clinical practice, the use of broad physiological end-points (i.e., urine output) and biochemical (i.e., serum creatinine, blood/urine urea nitrogen, and blood/urine electrolytes) are used. These indices are synthesised using RIFLE, AKIN, and calculations to determine the fractional excretion of sodium (FeNa) and urea (FeUrea) $[28,29,131]$. Calculation of GFR is extremely important in the evaluation of kidney function and can be achieved using a variety of methods. The use of gold standard filtration markers, such as inulin and iohexol, are limited in clinical practice [131]. However new techniques for determining GFR are emerging which may be beneficial in the setting of EAKI. These include the use of a transcutaneous remote real-time analysis of FITC-sinistrin excretion and a pointof-care bedside fluorescence-based measured GFR (mGFR) assay [131]. Other biochemical markers such as $\mathrm{fHb}$, plasmafree myoglobin, red cell distribution width (RDW), bilirubin, haptoglobin, plasma-free iron, hepcidin, plasma/urine albumin, and components of the renin-angiotensin aldosterone system (RAAS) may help to determine the risk and nature of EAKI $[82,95]$. Circulating levels of syndecan-1, endocan, and selectins may be useful markers of glycocalyx degradation $[48,132]$. Hemeprotein release and lipid peroxidation can be determined by the presence of elevated plasma/urine $\mathrm{F}_{2}$ isoprostanes and isofurans, which correlate with oxidative stress-mediated kidney damage [95].

Advanced physiological parameters can be obtained through invasive procedures. Renal and pulmonary artery transit-time flow probes with oximetry capability may facilitate a deeper understanding of EAKI. Moreover, they may allow accurate measurement of macro/microvascular flow, 
renal cortical and medullary tissue perfusion, and renal function throughout the entire course of ECMO in animal models [57, 133]. This can be achieved through an ultrasound-guided or surgically inserted renal artery catheter and subsequent assessment of renal blood flow, renal vascular conductance, and tissue oxygenation [57, 133]. Assessment of renal microcirculatory function and tissue oxygenation with near infrared spectroscopy (NIR), urine oxygen tension, tissue microdialysis, mitochondrial function analysis, and respiratory electron chain transport using Orboros may also provide investigative benefit [131].

5.2. Imaging. Imaging studies may be utilised to define the presence and severity of AKI in patients supported by ECMO. Renal ultrasound \pm Doppler is the most commonly utilised imaging modality for the assessment of patients with AKI [134]. Although there is no current data on its use in ECMO, it can be easily used in patients supported by ECMO and its utility should be investigated. Assessment of renal size, echogenicity, Doppler flow, and resistive index (RI) may help to predict, distinguish between causes, and provide prognostic information for AKI in patients on ECMO [57, 134-136]. However, limitations exist as RI can be influenced by a number of extrarenal factors such as heart rate and peripheral vascular resistance and therefore lacks specificity for AKI [137].

Contrast enhanced ultrasonography (CEU) uses contrast agents composed of microbubbles with an injectable gas in a supportive shell of phospholipids or proteins [138]. CEU can identify the intrinsic spatial and temporal heterogeneity of renal parenchymal perfusion [131, 139]. It has been shown to do this with a greater degree of accuracy compared to other imaging modalities, including magnetic resonance (MR) and computerised tomography (CT) [140]. Along with laser Doppler flowmetry, it is an ideal imaging modality for studying the microcirculation of organ blood flow/velocity patterns [141, 142]. Unlike other modalities $\mathrm{CEU}$ is safe, free of disruptive haemodynamic effects, and easy to utilise in patients on ECMO; however investigation into the destructive effects of the circuit interface on the concentration and utility of the contrast microspheres is warranted [143-145]. Due to logistical and incompatibility issues related to the ECMO circuit, recent advancements in other imaging modalities cannot be utilised to investigate EAKI. As such radiological assessment of renal medullary and cortical oxygenation in response to haemodynamic variables on ECMO is relatively limited.

5.3. Histological and Immunohistochemical. Renal biopsies in order to assess the presence, nature, and extent of AKI are not performed in patients on ECMO due to an unfavourable risk: benefit ratio; however, its use may be helpful in experimental animal models. Important pathophysiological factors may be identifiable through histological and immunohistochemical assessment of nephrons. Conventional staining methods combined with various immunohistochemical staining, apoptosis quantification, and gene expression for glycocalyx disruption and major controllers of vessel tone may delineate the cause and extent of EAKI. Among other methods, transmission electron microscopy (TEM) with ruthenium red, ferritin, lanthanum, and cupromeronic blue staining may help to specifically identify renal glycocalyx disruption [146]. Additionally, histological analysis with immunostaining of pimonidazole and the $\mathrm{Pd}$ phosphorescence technique can identify hypoxic areas of renal tissue, potentially highlighting an underlying heterogenous hypoxic nature of EAKI $[147,148]$.

\section{Potential Role of Biomarkers in ECMO-Associated Kidney Injury}

Whilst the role of novel biomarkers in AKI has shown promise they have been underutilised for patients on ECMO. In 2005, the Council of the American Society of Nephrology recommended that the highest research priority be the standardization and discovery of new biomarkers of AKI [149]. Following this, numerous publications outlining the use of many new biomarkers have emerged; however very few have been studied in patients on ECMO (Table 3: novel biomarkers) [150]. A number of biomarker-specific limitations and unresolved concerns have prevented their widespread use in clinical practice; however refinements are ongoing and an increase in clinical integration is likely to occur $[151,152]$.

Neutrophil gelatinase-associated lipocalin (NGAL) and cystatin $\mathrm{C}$ (CystC) have the greatest depth of research for the detection of AKI. Other promising biomarkers include kidney injury molecule-1 (KIM-1), renal-liver type fatty acid binding protein (L-FABP), insulin-like growth factor-binding protein 7 (IGFBP7), and tissue inhibitor of metalloproteinases-2 (TIMP-2). Combining these biomarkers may collectively improve the sensitivity and specificity of detecting AKI in patients supported by ECMO [153]. Novel biomarkers for AKI have been extensively assessed in the critical care setting and in patients supported by an ECC; however none have studied their utility in adults on ECMO [154-159]. Most of these markers can be easily measured in urine and plasma and their concentration increases with duration and severity of acute tubular injury [154, 155, 160163]. These biomarkers have demonstrated benefits in regard to early detection, need for RRT, recovery of kidney function, and prediction of prognosis of AKI in a variety of clinical settings $[37,44,105,113,150,157,159,163-179]$. Based on the incidence and clinical sequelae of EAKI, the utility of novel biomarkers in this cohort may be beneficial, particularly with regard to delineating major renal insult, and should be investigated.

Earlier detection of kidney injury using new biomarkers has led to the recognition of a subgroup of patients with "subclinical" or "incipient" AKI [161, 180-182]. "Subclinical AKI" is a term used to describe a state where tubular damage without glomerular function loss has occurred [180]. Moreover, it refers to when the RIFLE criteria are negative, but elevated levels of new biomarkers are present [180]. This subgroup is found to be associated with worse clinical outcomes [161, 180, 181]. Clinical use of "subclinical AKI" is not yet definitive as the specific clinical applications of biomarkers are currently undefined [152]. Nevertheless, 
investigating AKI with biomarkers has improved our understanding of pathophysiological processes and refined our approach to treatment strategies [151]. In the ECMO setting, biomarkers may be a vital tool for understanding whether initiation of ECMO is protective or destructive for renal function. Ultimately, earlier detection with biomarkers may enable early evidence-based risk stratification for diagnostic evaluation, monitoring AKI, and initiating/discontinuing "renal protective" interventions for patients on ECMO [183].

\section{Experimental Models to Investigate ECMO-Associated Kidney Injury}

The multitude of complex, interrelated variables present in patients on ECMO are difficult to control in a study setting. As a result, clinical research in patients on ECMO is challenging. Simulated ECC and in vivo animal models provide a valuable means to undertake detailed, systematic research into complex clinical scenarios and pathophysiological changes associated with ECMO [184]. Furthermore, in vivo models with large animal subjects may help to delineate and define the relative risk of EAKI. An in vivo ovine model has many advantages [10, 184]. Firstly, the overall size and weight are similar to humans. Secondly, sheep have similar renal anatomical structure, haemodynamic physiology, and microcirculatory function, which can be investigated with advanced methods/tools that are clinically applicable to human subjects $[10,145,185-187]$. Finally, ovine models have been used extensively throughout the literature for other human conditions [188-190].

An in vivo, ovine model of VV ECMO may successfully mimic the severity of patient illness and reproduce key haemodynamic and immunological aberrations. It can also serve as its own control, mimic histological findings in relevant organs, and provide a means to gain insight into factors contributing to interpatient variability [184]. Ultimately, an in vivo model will allow a thorough investigation into the renal response to various clinical conditions. Translational clinical investigations into EAKI will lead to a more accurate assessment of the relative contribution of ECMO circuit factors on renal function. Moreover, implementing novel renal monitoring modalities based on relevant pathophysiology will provide novel strategies for preventing/treating EAKI.

\section{Conclusion}

There are limited data within the literature exploring EAKI. Furthermore, there are no studies using RIFLE/AKIN in conjunction with advanced methods for investigating AKI in patients supported by ECMO. The high incidence rate of AKI in patients supported on ECMO and the subsequent mortality that emerges as a result of AKI is unacceptable. It is likely that EAKI exists as a dependent entity; however it is equally possible that initiation of ECMO serves to protect renal function. Understanding the patient-device interface and its role in the progression of normal renal function to AKI is imperative. This, in conjunction with earlier detection with the use of novel investigative methods, is fundamental step towards reducing EAKI. These issues can be investigated using an in vivo animal model with the goal to improve the understanding of the changes observed during ECMO and, subsequently, optimise the process. A better understanding of this will help to define optimal renal support for patients during therapy, ultimately reducing the risks associated with ECMO and improve patient survival.

\section{Conflict of Interests}

The authors declare that there is no conflict of interests regarding the publication of this paper.

\section{Acknowledgments}

John F. Fraser is currently supported by the Office of Health Medical Research Fellowship, Centre for Research Excellence NHMRC-ACTIONS, and The Prince Charles Hospital Foundation.

\section{References}

[1] K. Shekar, D. V. Mullany, B. Thomson, M. Ziegenfuss, D. G. Platts, and J. F. Fraser, "Extracorporeal life support devices and strategies for management of acute cardiorespiratory failure in adult patients: a comprehensive review," Critical Care, vol. 18, no. 3, article 219, 2014.

[2] G. J. Peek, M. Mugford, R. Tiruvoipati et al., "Efficacy and economic assessment of conventional ventilatory support versus extracorporeal membrane oxygenation for severe adult respiratory failure (CESAR): a multicentre randomised controlled trial," The Lancet, vol. 374, no. 9698, pp. 1351-1363, 2009.

[3] S. Allen, D. Holena, M. McCunn, B. Kohl, and B. Sarani, "A review of the fundamental principles and evidence base in the use of Extracorporeal Membrane Oxygenation (ECMO) in critically ill adult patients," Journal of Intensive Care Medicine, vol. 26, no. 1, pp. 13-26, 2011.

[4] N. Doll, B. Kiaii, M. Borger et al., "Five-year results of 219 consecutive patients treated with extracorporeal membrane oxygenation for refractory postoperative cardiogenic shock," The Annals of Thoracic Surgery, vol. 77, no. 1, pp. 151-157, 2004.

[5] N. G. Smedira, N. Moazami, C. M. Golding et al., "Clinical experience with 202 adults receiving extracorporeal membrane oxygenation for cardiac failure: survival at five years," The Journal of Thoracic and Cardiovascular Surgery, vol. 122, no. 1, pp. 92-102, 2001.

[6] R. H. Bartlett and L. Gattinoni, "Current status of extracorporeal life support (ECMO) for cardiopulmonary failure," Minerva Anestesiologica, vol. 76, no. 7, pp. 534-540, 2010.

[7] D. J. Askenazi, D. T. Selewski, M. L. Paden et al., "Renal replacement therapy in critically ill patients receiving extracorporeal membrane oxygenation," Clinical Journal of the American Society of Nephrology, vol. 7, no. 8, pp. 1328-1336, 2012.

[8] J. F. Fraser, K. Shekar, S. Diab et al., "ECMO-the clinician's view," ISBT Science Series, vol. 7, no. 1, pp. 82-88, 2012.

[9] H. J. Dalton, "Extracorporeal life support: moving at the speed of light," Respiratory Care, vol. 56, no. 9, pp. 1445-1453, 2011.

[10] Y. L. Fung, S. Diab, K. Dunster et al., "Extracorporeal lessons from sheep," ISBT Science Series, vol. 7, no. 1, pp. 92-95, 2012. 
[11] C.-Y. Lin, F.-C. Tsai, Y.-C. Tian et al., "Evaluation of outcome scoring systems for patients on extracorporeal membrane oxygenation," The Annals of Thoracic Surgery, vol. 84, no. 4, pp. 1256-1262, 2007.

[12] A. Zangrillo, G. Landoni, G. Biondi-Zoccai et al., "A metaanalysis of complications and mortality of extracorporeal membrane oxygenation," Critical Care and Resuscitation, vol. 15, no. 3, pp. 172-178, 2013.

[13] A. M. Gaffney, S. M. Wildhirt, M. J. Griffin, G. M. Annich, and M. W. Radomski, "Extracorporeal life support," British Medical Journal, vol. 341, Article ID c5317, 2010.

[14] W. Muntean, "Coagulation and anticoagulation in extracorporeal membrane oxygenation," Artificial Organs, vol. 23, no. 11, pp. 979-983, 1999.

[15] R. Cheng, R. Hachamovitch, M. Kittleson et al., "Complications of extracorporeal membrane oxygenation for treatment of cardiogenic shock and cardiac arrest: a meta-analysis of 1,866 adult patients," The Annals of Thoracic Surgery, vol. 97, no. 2, pp. 610-616, 2014.

[16] C.-C. Hsiao, C.-H. Chang, P.-C. Fan et al., "Prognosis of patients with acute respiratory distress syndrome on extracorporeal membrane oxygenation: the impact of urine output on mortality," The Annals of Thoracic Surgery, vol. 97, no. 6, pp. 1939-1944, 2014.

[17] J. T. Kielstein, A. M. Heiden, G. Beutel et al., "Renal function and survival in 200 patients undergoing ECMO therapy," Nephrology Dialysis Transplantation, vol. 28, no. 1, pp. 86-90, 2013.

[18] Y.-C. Chen, F.-C. Tsai, C.-H. Chang et al., "Prognosis of patients on extracorporeal membrane oxygenation: the impact of acute kidney injury on mortality," The Annals of Thoracic Surgery, vol. 91, no. 1, pp. 137-142, 2011.

[19] C.-Y. Lin, Y.-C. Chen, F.-C. Tsai et al., "RIFLE classification is predictive of short-term prognosis in critically ill patients with acute renal failure supported by extracorporeal membrane oxygenation," Nephrology Dialysis Transplantation, vol. 21, no. 10, pp. 2867-2873, 2006.

[20] G. Mariscalco, M. Cottini, C. Dominici et al., "The effect of timing of cardiac catheterization on acute kidney injury after cardiac surgery is influenced by the type of operation," International Journal of Cardiology, vol. 173, no. 1, pp. 46-54, 2014.

[21] R. Bellomo, J. A. Kellum, and C. Ronco, "Acute kidney injury," The Lancet, vol. 380, no. 9843, pp. 756-766, 2012.

[22] S. M. Bagshaw, C. George, R. Bellomo, and Committee ADM, "Changes in the incidence and outcome for early acute kidney injury in a cohort of Australian intensive care units," Critical Care, vol. 11, no. 3, article R68, 2007.

[23] S. M. Bagshaw, C. George, I. Dinu, and R. Bellomo, "A multicentre evaluation of the RIFLE criteria for early acute kidney injury in critically ill patients," Nephrology Dialysis Transplantation, vol. 23, no. 4, pp. 1203-1210, 2008.

[24] R. Bellomo, C. Ronco, J. A. Kellum, R. L. Mehta, and P. Palevsky, "Acute Dialysis Quality Initiative w. Acute renal failuredefinition, outcome measures, animal models, fluid therapy and information technology needs: the second International Consensus Conference of the Acute Dialysis Quality Initiative (ADQI) Group," Critical Care, vol. 8, no. 4, pp. R204-R212, 2004.

[25] S. M. Bagshaw, "Acute kidney injury: diagnosis and classification of AKI: AKIN or RIFLE?" Nature Reviews Nephrology, vol. 6, no. 2, pp. 71-73, 2010.
[26] R. Bellomo, J. Kellum, and C. Ronco, "Acute renal failure: time for consensus," Intensive Care Medicine, vol. 27, no. 11, pp. 1685$1688,2001$.

[27] G. M. Chertow, E. Burdick, M. Honour, J. V. Bonventre, and D. W. Bates, "Acute kidney injury, mortality, length of stay, and costs in hospitalized patients," Journal of the American Society of Nephrology, vol. 16, no. 11, pp. 3365-3370, 2005.

[28] R. Bellomo, J. A. Kellum, and C. Ronco, "Defining and classifying acute renal failure: from advocacy to consensus and validation of the RIFLE criteria," Intensive Care Medicine, vol. 33, no. 3, pp. 409-413, 2007.

[29] M. Joannidis, B. Metnitz, P. Bauer et al., "Acute kidney injury in critically ill patients classified by AKIN versus RIFLE using the SAPS 3 database," Intensive Care Medicine, vol. 35, no. 10, pp. 1692-1702, 2009.

[30] National Guideline Clearinghouse, KDIGO Clinical Practice Guideline for Acute Kidney Injury, Agency for Healthcare Research and Quality (AHRQ), Rockville, Md, USA, 2013, http://www.guideline.gov/content.aspx?id=38024.

[31] X. Yan, S. Jia, X. Meng et al., "Acute kidney injury in adult postcardiotomy patients with extracorporeal membrane oxygenation: evaluation of the RIFLE classification and the Acute Kidney Injury Network criteria," European Journal of Cardiothoracic Surgery, vol. 37, no. 2, pp. 334-338, 2010.

[32] M. Ostermann and R. W. S. Chang, "Acute kidney injury in the intensive care unit according to RIFLE," Critical Care Medicine, vol. 35, no. 8, pp. 1837-1852, 2007.

[33] E. A. J. Hoste, G. Clermont, A. Kersten et al., "RIFLE criteria for acute kidney injury are associated with hospital mortality in critically ill patients: a cohort analysis," Critical Care, vol. 10, no. 3, article R73, 2006.

[34] A. Kuitunen, A. Vento, R. Suojaranta-Ylinen, and V. Pettilä, "Acute renal failure after cardiac surgery: evaluation of the RIFLE classification," The Annals of Thoracic Surgery, vol. 81, no. 2, pp. 542-546, 2006.

[35] S. Uchino, R. Bellomo, D. Goldsmith, S. Bates, and C. Ronco, "An assessment of the RIFLE criteria for acute renal failure in hospitalized patients," Critical Care Medicine, vol. 34, no. 7, pp. 1913-1917, 2006.

[36] M. Haase, R. Bellomo, G. Matalanis, P. Calzavacca, D. Dragun, and A. Haase-Fielitz, "A comparison of the RIFLE and Acute Kidney Injury Network classifications for cardiac surgeryassociated acute kidney injury: a prospective cohort study," Journal of Thoracic and Cardiovascular Surgery, vol. 138, no. 6, pp. 1370-1376, 2009.

[37] Z. Ricci, D. N. Cruz, and C. Ronco, "Classification and staging of acute kidney injury: beyond the RIFLE and AKIN criteria," Nature Reviews Nephrology, vol. 7, no. 4, pp. 201-208, 2011.

[38] Z. Ricci, D. Cruz, and C. Ronco, "The RIFLE criteria and mortality in acute kidney injury: a systematic review," Kidney International, vol. 73, no. 5, pp. 538-546, 2008.

[39] J.-L. Vincent, Annual Update in Intensive Care and Emergency Medicine 2013, Springer, Dordrecht, The Netherlands, 2013, http:// BOND.eblib.com.au/patron/FullRecord.aspx?p=1082878.

[40] S. Uchino, R. Bellomo, S. M. Bagshaw, and D. Goldsmith, "Transient azotaemia is associated with a high risk of death in hospitalized patients," Nephrology Dialysis Transplantation, vol. 25, no. 6, pp. 1833-1839, 2010.

[41] A. C. K. Chung and H. Y. Lan, "Chemokines in renal injury," Journal of the American Society of Nephrology, vol. 22, no. 5, pp. 802-809, 2011. 
[42] A. B. Kumar and M. Suneja, "Cardiopulmonary bypassassociated acute kidney injury," Anesthesiology, vol. 114, no. 4, pp. 964-970, 2011.

[43] M. D. Okusa, "The inflammatory cascade in acute ischemic renal failure," Nephron, vol. 90, no. 2, pp. 133-138, 2002.

[44] C. Ronco, M. Haapio, A. A. House, N. Anavekar, and R. Bellomo, "Cardiorenal syndrome," Journal of the American College of Cardiology, vol. 52, no. 19, pp. 1527-1539, 2008.

[45] B. B. Ratliff, M. M. Rabadi, R. Vasko, K. Yasuda, and M. S. Goligorsky, "Messengers without borders: mediators of systemic inflammatory response in AKI," Journal of the American Society of Nephrology, vol. 24, no. 4, pp. 529-536, 2013.

[46] M. Hirthler, J. Simoni, and M. Dickson, "Elevated levels of endotoxin, oxygen-derived free radicals, and cytokines during extracorporeal membrane oxygenation," Journal of Pediatric Surgery, vol. 27, no. 9, pp. 1199-1202, 1992.

[47] C. Ince, "The central role of renal microcirculatory dysfunction in the pathogenesis of acute kidney injury," Nephron Clinical Practice, vol. 127, no. 1-4, pp. 124-128, 2014.

[48] C. Chelazzi, G. Villa, P. Mancinelli, A. De Gaudio, and C. Adembri, "Glycocalyx and sepsis-induced alterations in vascular permeability," Critical Care, vol. 19, no. 1, article 26, 2015.

[49] A. Gluba, M. Banach, S. Hannam, D. P. Mikhailidis, A. Sakowicz, and J. Rysz, "The role of Toll-like receptors in renal diseases," Nature Reviews Nephrology, vol. 6, no. 4, pp. 224-235, 2010.

[50] S. Swaminathan, M. H. Rosner, and M. D. Okusa, "Emerging therapeutic targets of sepsis-associated acute kidney injury," Seminars in Nephrology, vol. 35, no. 1, pp. 38-54, 2015.

[51] G. R. Kinsey, L. Li, and M. D. Okusa, "Inflammation in acute kidney injury," Nephron Experimental Nephrology, vol. 109, no. 4, pp. e102-e107, 2008.

[52] M. Ikeda, W. Prachasilchai, M. J. Burne-Taney, H. Rabb, and N. Yokota-Ikeda, "Ischemic acute tubular necrosis models and drug discovery: a focus on cellular inflammation," Drug Discovery Today, vol. 11, no. 7-8, pp. 364-370, 2006.

[53] T. Johannes, E. G. Mik, K. Klingel, H.-J. Dieterich, K. E. Unertl, and C. Ince, "Low-dose dexamethasone-supplemented fluid resuscitation reverses endotoxin-induced acute renal failure and prevents cortical microvascular hypoxia," Shock, vol. 31, no. 5, pp. 521-528, 2009.

[54] C. Langenberg, R. Bellomo, C. May, L. Wan, M. Egi, and S. Morgera, "Renal blood flow in sepsis," Critical Care, vol. 9, no. 4, pp. R363-R374, 2005.

[55] A. Bouglé and J. Duranteau, "Pathophysiology of sepsisinduced acute kidney injury: the role of global renal blood flow and renal vascular resistance," Contributions to Nephrology, vol. 174, pp. 89-97, 2011.

[56] D. Di Giantomasso, H. Morimatsu, C. N. May, and R. Bellomo, "Intrarenal blood flow distribution in hyperdynamic septic shock: effect of norepinephrine," Critical Care Medicine, vol. 31, no. 10, pp. 2509-2513, 2003.

[57] C. Langenberg, L. Wan, M. Egi, C. N. May, and R. Bellomo, "Renal blood flow in experimental septic acute renal failure," Kidney International, vol. 69, no. 11, pp. 1996-2002, 2006.

[58] C.-L. Leong, W. P. Anderson, P. M. O'Connor, and R. G. Evans, "Evidence that renal arterial-venous oxygen shunting contributes to dynamic regulation of renal oxygenation," The American Journal of Physiology-Renal Physiology, vol. 292, no. 6, pp. F1726-F1733, 2007.

[59] D. Casellas and A. Mimran, "Shunting in renal microvasculature of the rat: a scanning electron microscopic study of corrosion casts," The Anatomical Record, vol. 201, no. 2, pp. 237248, 1981.

[60] R. G. Evans, B. S. Gardiner, D. W. Smith, and P. M. O'Connor, "Intrarenal oxygenation: unique challenges and the biophysical basis of homeostasis," American Journal of Physiology-Renal Physiology, vol. 295, no. 5, pp. F1259-F1270, 2008.

[61] A. Ljungqvist, "Ultrastructural demonstration of a connection between afferent and efferent juxtamedullary glomerular arterioles," Kidney International, vol. 8, no. 4, pp. 239-244, 1975.

[62] J. F. Heggie, “Isaacs-Ludwig arteriole,” The Lancet, vol. 249, no. 6461, p. 926, 1947.

[63] Y. Sakr, M. J. Dubois, D. De Backer, J. Creteur, and J. L. Vincent, "Persistent microcirculatory alterations are associated with organ failure and death in patients with septic shock," Critical Care Medicine, vol. 32, no. 9, pp. 1825-1831, 2004.

[64] J. Cohen, “The immunopathogenesis of sepsis," Nature, vol. 420, no. 6917, pp. 885-891, 2002.

[65] H. Kolářová, B. Ambrůzová, L. Švihálková Šindlerová, A. Klinke, and L. Kubala, "Modulation of endothelial glycocalyx structure under inflammatory conditions," Mediators of Inflammation, vol. 2014, Article ID 694312, 17 pages, 2014.

[66] A. H. Salmon and S. C. Satchell, "Endothelial glycocalyx dysfunction in disease: albuminuria and increased microvascular permeability," The Journal of Pathology, vol. 226, no. 4, pp. 562574, 2012.

[67] M. Legrand, E. G. Mik, T. Johannes, D. Payen, and C. Ince, "Renal hypoxia and dysoxia after reperfusion of the ischemic kidney," Molecular Medicine, vol. 14, no. 7-8, pp. 502-516, 2008.

[68] M. Legrand, R. Bezemer, A. Kandil, C. Demirci, D. Payen, and C. Ince, "The role of renal hypoperfusion in development of renal microcirculatory dysfunction in endotoxemic rats," Intensive Care Medicine, vol. 37, no. 9, pp. 1534-1542, 2011.

[69] K. Shekar and J. F. Fraser, "Can timely ECMO initiation mitigate pre-ECMO risk factors for acute kidney injury?" The Annals of Thoracic Surgery, vol. 98, no. 4, p. 1523, 2014.

[70] W. Wang, S. Jittikanont, S. A. Falk et al., "Interaction among nitric oxide, reactive oxygen species, and antioxidants during endotoxemia-related acute renal failure," The American Journal of Physiology-Renal Physiology, vol. 284, no. 3, pp. F532-F537, 2003.

[71] T. Yoshioka and I. Ichikawa, "Glomerular dysfunction induced by polymorphonuclear leukocyte-derived reactive oxygen species," The American Journal of Physiology, vol. 257, no. 1, part 2, pp. F53-F59, 1989.

[72] N. D. Vaziri, M. Dicus, N. D. Ho, L. Boroujerdi-Rad, and R. K. Sindhu, "Oxidative stress and dysregulation of superoxide dismutase and NADPH oxidase in renal insufficiency," Kidney International, vol. 63, no. 1, pp. 179-185, 2003.

[73] H. Gomez, C. Ince, D. De Backer et al., "A unified theory of sepsis-induced acute kidney injury: inflammation, microcirculatory dysfunction, bioenergetics, and the tubular cell adaptation to injury," Shock, vol. 41, no. 1, pp. 3-11, 2014.

[74] N. K. Patil, N. Parajuli, L. A. MacMillan-Crow, and P. R. Mayeux, "Inactivation of renal mitochondrial respiratory complexes and manganese superoxide dismutase during sepsis: mitochondriatargeted antioxidant mitigates injury," American Journal of Physiology Renal Physiology, vol. 306, no. 7, pp. F734-F743, 2014.

[75] K. S. Echtay, T. C. Esteves, J. L. Pakay et al., "A signalling role for 4-hydroxy-2-nonenal in regulation of mitochondrial uncoupling," The EMBO Journal, vol. 22, no. 16, pp. 4103-4110, 2003. 
[76] J. P. Moore, A. Dyson, M. Singer, J. Fraser, and J. G. Hardman, "Microcirculatory dysfunction and resuscitation: why, when, and how," British Journal of Anaesthesia, vol. 115, no. 3, pp. 366375, 2015.

[77] M. Legrand, E. G. Mik, G. M. Balestra et al., "Fluid resuscitation does not improve renal oxygenation during hemorrhagic shock in rats," Anesthesiology, vol. 112, no. 1, pp. 119-127, 2010.

[78] D. R. Salgado, X. He, F. Su et al., "Sublingual microcirculatory effects of enalaprilat in an ovine model of septic shock," Shock, vol. 35, no. 6, pp. 542-549, 2011.

[79] L. Wan, C. Langenberg, R. Bellomo, and C. N. May, "Angiotensin II in experimental hyperdynamic sepsis," Critical Care, vol. 13, no. 6, article R190, 2009.

[80] K. Ishikawa, P. Calzavacca, R. Bellomo, M. Bailey, and C. N. May, "Effect of selective inhibition of renal inducible nitric oxide synthase on renal blood flow and function in experimental hyperdynamic sepsis," Critical Care Medicine, vol. 40, no. 8, pp. 2368-2375, 2012.

[81] C. Ince, "The rationale for microcirculatory guided fluid therapy," Current Opinion in Critical Care, vol. 20, no. 3, pp. 301-308, 2014.

[82] M. Haase, R. Bellomo, and A. Haase-Fielitz, "Novel biomarkers, oxidative stress, and the role of labile iron toxicity in cardiopulmonary bypass-associated acute kidney injury," Journal of the American College of Cardiology, vol. 55, no. 19, pp. 2024-2033, 2010.

[83] L. Vercaemst, "Hemolysis in cardiac surgery patients undergoing cardiopulmonary bypass: a review in search of a treatment algorithm," The Journal of Extra-Corporeal Technology, vol. 40, no. 4, pp. 257-267, 2008.

[84] Z. Ricci, C. Pezzella, S. Romagnoli et al., "High levels of free haemoglobin in neonates and infants undergoing surgery on cardiopulmonary bypass," Interactive Cardiovascular and Thoracic Surgery, vol. 19, no. 2, pp. 183-187, 2014.

[85] J.-J. Lahet, C. Courderot-Masuyer, F. Lenfant et al., "The influence of extracorporeal circulation on the susceptibility of erythrocytes to oxidative stress," Free Radical Research, vol. 38, no. 7, pp. 683-689, 2004.

[86] D. C. C. Williams, J. L. L. Turi, C. P. P. Hornik et al., "Circuit oxygenator contributes to extracorporeal membrane oxygenation-induced hemolysis," ASAIO Journal, vol. 61, no. 2, pp. 190-195, 2015.

[87] C. I. McDonald, J. F. Fraser, J. S. Coombes, and Y. L. Fung, "Oxidative stress during extracorporeal circulation," European Journal of Cardio-Thoracic Surgery, vol. 46, no. 6, pp. 937-943, 2014.

[88] M. J. Simmonds, N. Atac, O. K. Baskurt, H. J. Meiselman, and O. Yalcin, "Erythrocyte deformability responses to intermittent and continuous subhemolytic shear stress," Biorheology, vol. 51, no. 2-3, pp. 171-185, 2014.

[89] H. Yamaguchi, T. Shimizu, H. Akutsu et al., "Hemolysis and red cell deformability during cardiopulmonary bypass-the effect of prostaglandin E1 for prevention of hemolysis," Nihon Kyobu Geka Gakkai, vol. 38, no. 4, pp. 625-629, 1990.

[90] U. M. Fischer, W. K. Weissenberger, R. D. Warters, H. J. Geissler, S. J. Allen, and U. Mehlhorn, "Impact of cardiopulmonary bypass management on postcardiac surgery renal function," Perfusion, vol. 17, no. 6, pp. 401-406, 2002.

[91] J. Boldt, T. Brenner, A. Lehmann, S. W. Suttner, B. Kumle, and F. Isgro, "Is kidney function altered by the duration of cardiopulmonary bypass?" The Annals of Thoracic Surgery, vol. 75, no. 3, pp. 906-912, 2003.
[92] S. Lou, G. MacLaren, D. Best, C. Delzoppo, and W. Butt, "Hemolysis in pediatric patients receiving centrifugal-pump extracorporeal membrane oxygenation: prevalence, risk factors, and outcomes," Critical Care Medicine, vol. 42, no. 5, pp. 12131220, 2014.

[93] U. Aksu, C. Demirci, and C. Ince, "The pathogenesis of acute kidney injury and the toxic triangle of oxygen, reactive oxygen species and nitric oxide," Contributions to Nephrology, vol. 174, pp. 119-128, 2011.

[94] I. C. Vermeulen Windsant, S. J. Hanssen, W. A. Buurman, and M. J. Jacobs, "Cardiovascular surgery and organ damage: time to reconsider the role of hemolysis," The Journal of Thoracic and Cardiovascular Surgery, vol. 142, no. 1, pp. 1-11, 2011.

[95] F. T. Billings IV, S. K. Ball, L. J. Roberts II, and M. Pretorius, "Postoperative acute kidney injury is associated with hemoglobinemia and an enhanced oxidative stress response," Free Radical Biology \& Medicine, vol. 50, no. 11, pp. 1480-1487, 2011.

[96] R. A. Zager and L. M. Gamelin, "Pathogenetic mechanisms in experimental hemoglobinuric acute renal failure," The American Journal of Physiology, vol. 256, no. 3, part 2, pp. F446-F455, 1989.

[97] H. R. Omar, M. Mirsaeidi, S. Socias et al., "Plasma free hemoglobin is an independent predictor of mortality among patients on extracorporeal membrane oxygenation support," PLoS ONE, vol. 10, no. 4, Article ID e0124034, 2015.

[98] J. M. C. Gutteridge, "Iron promoters of the Fenton reaction and lipid peroxidation can be released from haemoglobin by peroxides," FEBS Letters, vol. 201, no. 2, pp. 291-295, 1986.

[99] B. Halliwell and J. M. C. Gutteridge, "Role of free radicals and catalytic metal ions in human disease: an overview," Methods in Enzymology, vol. 186, pp. 1-85, 1990.

[100] D. K. Das, R. M. Engelman, X. Liu et al., "Oxygen-derived free radicals and hemolysis during open heart surgery," Molecular and Cellular Biochemistry, vol. 111, no. 1-2, pp. 77-86, 1992.

[101] M. Haase, A. Haase-Fielitz, S. M. Bagshaw, C. Ronco, and R. Bellomo, "Cardiopulmonary bypass-associated acute kidney injury: a pigment nephropathy?" Contributions to Nephrology, vol. 156, pp. 340-353, 2007.

[102] R. P. Rother, L. Bell, P. Hillmen, and M. T. Gladwin, "The clinical sequelae of intravascular hemolysis and extracellular plasma hemoglobin: a novel mechanism of human disease," The Journal of the American Medical Association, vol. 293, no. 13, pp. 16531662, 2005.

[103] C. I. McDonald, Y. L. Fung, K. Shekar et al., "The impact of acute lung injury, ECMO and transfusion on oxidative stress and plasma selenium levels in an ovine model," Journal of Trace Elements in Medicine and Biology, vol. 30, pp. 4-10, 2015.

[104] R. A. Hayes, K. Shekar, and J. F. Fraser, "Is hyperoxaemia helping or hurting patients during extracorporeal membrane oxygenation? Review of a complex problem," Perfusion, vol. 28, no. 3, pp. 184-193, 2013.

[105] S. Pesic, M. Milinkovic, M. Vuletic et al., "Assessment of oxidative status in patients with acute kidney injury: a pilot study," The Chinese Journal of Physiology, vol. 58, no. 2, pp. 124133, 2015.

[106] A. Singh, R. D. Ramnath, R. R. Foster et al., "Reactive oxygen species modulate the barrier function of the human glomerular endothelial glycocalyx," PLoS ONE, vol. 8, no. 2, Article ID e55852, 2013.

[107] M. T. Gladwin, J. H. Crawford, and R. P. Patel, "The biochemistry of nitric oxide, nitrite, and hemoglobin: role in blood flow 
regulation," Free Radical Biology \& Medicine, vol. 36, no. 6, pp. 707-717, 2004.

[108] K. Tanaka, Y. Kanamori, T. Sato et al., "Administration of haptoglobin during cardiopulmonary bypass surgery," ASAIO Transactions, vol. 37, no. 3, pp. M482-M483, 1991.

[109] T. U. Ohshiro, K. Mukai, and G. Kosaki, "Prevention of hemoglobinuria by administration of haptoglobin," Research in Experimental Medicine, vol. 177, no. 1, pp. 1-12, 1980.

[110] H. Nagara, M. Atobe, H. Hiratsuka, and J. Wada, "Administration of haptoglobin in open heart surgery: prevention of hemoglobinuria (author's transl)," Nihon Kyobu Geka Gakkai, vol. 27, no. 3, pp. 257-262, 1979.

[111] T. Yoshioka, T. Sugimoto, T. Ukai, and T. Oshiro, "Haptoglobin therapy for possible prevention of renal failure following thermal injury: a clinical study," The Journal of Trauma, vol. 25, no. 4, pp. 281-287, 1985.

[112] M. S. Paller, "Hemoglobin- and myoglobin-induced acute renal failure in rats: role of iron in nephrotoxicity," The American Journal of Physiology, vol. 255, no. 3, part 2, pp. F539-F544, 1988.

[113] S. V. Shah and P. D. Walker, "Evidence suggesting a role for hydroxyl radical in glycerol-induced acute renal failure," The American Journal of Physiology, vol. 255, no. 3, part 2, pp. F438F443, 1988.

[114] J. L. Koyner, R. Sher Ali, and P. T. Murray, "Antioxidants. Do they have a place in the prevention or therapy of acute kidney injury?" Nephron Experimental Nephrology, vol. 109, no. 4, pp. e109-e117, 2008.

[115] K. Ware, Z. Qamri, A. Ozcan et al., "N-acetylcysteine ameliorates acute kidney injury but not glomerular hemorrhage in an animal model of warfarin-related nephropathy," American Journal of Physiology-Renal Physiology, vol. 304, no. 12, pp. F1421-F1427, 2013.

[116] U. Sadat, A. Usman, J. H. Gillard, and J. R. Boyle, "Does ascorbic acid protect against contrast-induced acute kidney injury in patients undergoing coronary angiography: a systematic review with meta-analysis of randomized, controlled trials," Journal of the American College of Cardiology, vol. 62, no. 23, pp. 2167-2175, 2013.

[117] D. Schwartz, M. Mendonca, I. Schwartz et al., "Inhibition of constitutive nitric oxide synthase (NOS) by nitric oxide generated by inducible NOS after lipopolysaccharide administration provokes renal dysfunction in rats," The Journal of Clinical Investigation, vol. 100, no. 2, pp. 439-448, 1997.

[118] M. Legrand, E. Almac, E. G. Mik et al., "L-NIL prevents renal microvascular hypoxia and increase of renal oxygen consumption after ischemia-reperfusion in rats," American Journal of Physiology-Renal Physiology, vol. 296, no. 5, pp. F1109-F1117, 2009.

[119] M. Legrand, A. Kandil, D. Payen, and C. Ince, "Effects of sepiapterin infusion on renal oxygenation and early acute renal injury after suprarenal aortic clamping in rats," Journal of Cardiovascular Pharmacology, vol. 58, no. 2, pp. 192-198, 2011.

[120] T. Johannes, C. Ince, K. Klingel, K. E. Unertl, and E. G. Mik, "Iloprost preserves renal oxygenation and restores kidney function in endotoxemia-related acute renal failure in the rat," Critical Care Medicine, vol. 37, no. 4, pp. 1423-1432, 2009.

[121] R. C. Reed and J. C. Rutledge, "Laboratory and clinical predictors of thrombosis and hemorrhage in 29 pediatric extracorporeal membrane oxygenation nonsurvivors," Pediatric and Developmental Pathology, vol. 13, no. 5, pp. 385-392, 2010.
[122] A. C. Frati-Munari, "Medical significance of endothelial glycocalyx," Archivos de Cardiologia de Mexico, vol. 83, no. 4, pp. 303312, 2013.

[123] W.-W. Chang, F.-C. Tsai, T.-Y. Tsai et al., "Predictors of mortality in patients successfully weaned from extracorporeal membrane oxygenation," PLoS ONE, vol. 7, no. 8, Article ID e42687, 2012.

[124] Z. Ricci and C. Ronco, "Pulmonary/renal interaction," Current Opinion in Critical Care, vol. 16, no. 1, pp. 13-18, 2010.

[125] J. P. C. van den Akker, M. Egal, and J. A. B. Groeneveld, "Invasive mechanical ventilation as a risk factor for acute kidney injury in the critically ill: a systematic review and meta-analysis," Critical Care, vol. 17, no. 3, article R98, 2013.

[126] L. P. Jacob, J.-J. A. Chazalet, D. M. Payen et al., "Renal hemodynamic and functional effect of PEEP ventilation in human renal transplantations," American Journal of Respiratory and Critical Care Medicine, vol. 152, no. 1, pp. 103-107, 1995.

[127] J. R. Prowle, M. P. Molan, E. Hornsey, and R. Bellomo, "Measurement of renal blood flow by phase-contrast magnetic resonance imaging during septic acute kidney injury: a pilot investigation," Critical Care Medicine, vol. 40, no. 6, pp. 17681776, 2012.

[128] M. Schmidt, M. Bailey, J. Kelly et al., "Impact of fluid balance on outcome of adult patients treated with extracorporeal membrane oxygenation," Intensive Care Medicine, vol. 40, no. 9, pp. 1256-1266, 2014.

[129] A. J. M. Zwiers, K. Cransberg, J. van Rosmalen, E. D. Wildschut, D. Tibboel, and S. N. de Wildt, "Loop diuretics are an independent risk factor for acute kidney injury in children on extracorporeal membrane oxygenation with pre-emptive continuous hemofiltration," Intensive Care Medicine, vol. 40, no. 4, pp. 627-628, 2014.

[130] S. Salis, V. V. Mazzanti, G. Merli et al., "Cardiopulmonary bypass duration is an independent predictor of morbidity and mortality after cardiac surgery," Journal of Cardiothoracic and Vascular Anesthesia, vol. 22, no. 6, pp. 814-822, 2008.

[131] M. D. Okusa, B. L. Jaber, P. Doran et al., "Physiological biomarkers of acute kidney injury: a conceptual approach to improving outcomes," Contributions to Nephrology, vol. 182, pp. 65-81, 2013.

[132] R. J. Haywood-Watson, J. B. Holcomb, E. A. Gonzalez et al., "Modulation of syndecan-1 shedding after hemorrhagic shock and resuscitation," PLoS ONE, vol. 6, no. 8, Article ID e23530, 2011.

[133] C. Langenberg, L. Wan, M. Egi, C. N. May, and R. Bellomo, "Renal blood flow and function during recovery from experimental septic acute kidney injury," Intensive Care Medicine, vol. 33, no. 9, pp. 1614-1618, 2007.

[134] S. Faubel, N. U. Patel, M. E. Lockhart, and M. A. Cadnapaphornchai, "Renal relevant radiology: use of ultrasonography in patients with AKI," Clinical Journal of the American Society of Nephrology, vol. 9, no. 2, pp. 382-394, 2014.

[135] G. Bossard, P. Bourgoin, J. J. Corbeau, J. Huntzinger, and L. Beydon, "Early detection of postoperative acute kidney injury by Doppler renal resistive index in cardiac surgery with cardiopulmonary bypass," British Journal of Anaesthesia, vol. 107, no. 6, pp. 891-898, 2011.

[136] D. Schnell and M. Darmon, "Renal Doppler to assess renal perfusion in the critically ill: a reappraisal," Intensive Care Medicine, vol. 38, no. 11, pp. 1751-1760, 2012.

[137] W. C. O’Neill, "Renal relevant radiology: use of ultrasound in kidney disease and nephrology procedures," Clinical Journal of 
the American Society of Nephrology, vol. 9, no. 2, pp. 373-381, 2014.

[138] A. Schneider, L. Johnson, M. Goodwin, A. Schelleman, and R. Bellomo, "Bench-to-bedside review: contrast enhanced ultrasonography - a promising technique to assess renal perfusion in the ICU," Critical Care, vol. 15, no. 3, article 157, 2011.

[139] S. B. Feinstein, B. Coll, D. Staub et al., "Contrast enhanced ultrasound imaging," Journal of Nuclear Cardiology, vol. 17, no. 1, pp. 106-115, 2010.

[140] B. A. Kaufmann, K. Wei, and J. R. Lindner, "Contrast echocardiography," Current Problems in Cardiology, vol. 32, no. 2, pp. 51-96, 2007.

[141] J. R. Lindner, J. Song, A. R. Jayaweera, J. Sklenar, and S. Kaul, "Microvascular rheology of definity microbubbles after intra-arterial and intravenous administration," Journal of the American Society of Echocardiography, vol. 15, no. 5, pp. 396403, 2002.

[142] D. De Backer, G. Ospina-Tascon, D. Sagado, R. Favory, J. Creteur, and J.-L. Vincent, "Monitoring the microcirculation in the critically ill patient: current methods and future approaches," Intensive Care Medicine, vol. 36, no. 11, pp. 1813-1825, 2010.

[143] K. Kalantarinia, "Novel imaging techniques in acute kidney injury," Current Drug Targets, vol. 10, no. 12, pp. 1184-1189, 2009.

[144] A. Harrois and J. Duranteau, "Contrast-enhanced ultrasound: a new vision of microcirculation in the intensive care unit," Critical Care, vol. 17, no. 4, article 449, 2013.

[145] D. G. Platts, S. Diab, K. R. Dunster et al., "Feasibility of perflutren microsphere contrast transthoracic echocardiography in the visualization of ventricular endocardium during venovenous extracorporeal membrane oxygenation in a validated ovine model," Echocardiography, vol. 32, no. 3, pp. 548-556, 2015.

[146] M. J. Dane, B. M. van den Berg, D. H. Lee et al., "A microscopic view on the renal endothelial glycocalyx," The American Journal of Physiology-Renal Physiology, vol. 308, no. 9, pp. F956-F966, 2015.

[147] T. Johannes, E. G. Mik, and C. Ince, "Nonresuscitated endotoxemia induces microcirculatory hypoxic areas in the renal cortex in the rat," Shock, vol. 31, no. 1, pp. 97-103, 2009.

[148] A. Abdelkader, J. Ho, C. P. C. Ow et al., "Renal oxygenation in acute renal ischemia-reperfusion injury," American Journal of Physiology-Renal Physiology, vol. 306, no. 9, pp. F1026-F1038, 2014.

[149] American Society of Nephrology, "American Society of Nephrology renal research report," Journal of the American Society of Nephrology, vol. 16, no. 7, pp. 1886-1903, 1886.

[150] C. R. Parikh and A. X. Garg, "Testing new biomarkers for acute kidney injury: association, prediction, and intervention," American Journal of Kidney Diseases, vol. 54, no. 6, pp. 987-989, 2009.

[151] M. Legrand and M. Darmon, "Biomarkers for AKI improve clinical practice: yes," Intensive Care Medicine, vol. 41, no. 4, pp. 615-617, 2015.

[152] M. Ostermann and M. Joannidis, "Biomarkers for AKI improve clinical practice: no," Intensive Care Medicine, vol. 41, no. 4, pp. 618-622, 2015.

[153] A. Haase-Fielitz, M. Haase, and P. Devarajan, "Neutrophil gelatinase-associated lipocalin as a biomarker of acute kidney injury: a critical evaluation of current status," Annals of Clinical Biochemistry, vol. 51, no. 3, pp. 335-351, 2014.
[154] M. Haase, R. Bellomo, P. Devarajan et al., "Accuracy of neutrophil gelatinase-associated lipocalin (NGAL) in diagnosis and prognosis in acute kidney injury: a systematic review and metaanalysis," American Journal of Kidney Diseases, vol. 54, no. 6, pp. 1012-1024, 2009.

[155] D. N. Cruz, M. de Cal, F. Garzotto et al., "Plasma neutrophil gelatinase-associated lipocalin is an early biomarker for acute kidney injury in an adult ICU population," Intensive Care Medicine, vol. 36, no. 3, pp. 444-451, 2010.

[156] H. R. de Geus, J. G. Woo, Y. Wang et al., "Urinary neutrophil gelatinase-associated lipocalin measured on admission to the intensive care unit accurately discriminates between sustained and transient acute kidney injury in adult critically ill patients," Nephron Extra, vol. 1, no. 1, pp. 9-23, 2011.

[157] Z. H. Endre, J. W. Pickering, R. J. Walker et al., "Improved performance of urinary biomarkers of acute kidney injury in the critically ill by stratification for injury duration and baseline renal function," Kidney International, vol. 79, no. 10, pp. 11191130, 2011.

[158] N. I. Shapiro, S. Trzeciak, J. E. Hollander et al., "The diagnostic accuracy of plasma neutrophil gelatinase-associated lipocalin in the prediction of acute kidney injury in emergency department patients with suspected sepsis," Annals of Emergency Medicine, vol. 56, no. 1, pp. 52-59.e1, 2010.

[159] H. R. H. de Geus, J. Bakker, E. M. E. H. Lesaffre, and J. L. M. L. le Noble, "Neutrophil gelatinase-associated lipocalin at ICU admission predicts for acute kidney injury in adult patients," American Journal of Respiratory and Critical Care Medicine, vol. 183, no. 7, pp. 907-914, 2011.

[160] T. L. Nickolas, K. M. Schmidt-Ott, P. Canetta et al., "Diagnostic and prognostic stratification in the emergency department using urinary biomarkers of nephron damage: a multicenter prospective cohort study," Journal of the American College of Cardiology, vol. 59, no. 3, pp. 246-255, 2012.

[161] M. Haase, P. Devarajan, A. Haase-Fielitz et al., "The outcome of neutrophil gelatinase-associated lipocalin-positive subclinical acute kidney injury: a multicenter pooled analysis of prospective studies," Journal of the American College of Cardiology, vol. 57, no. 17, pp. 1752-1761, 2011.

[162] D. Shemin and L. D. Dworkin, "Neutrophil gelatinaseassociated lipocalin (NGAL) as a biomarker for early acute kidney injury," Critical Care Clinics, vol. 27, no. 2, pp. 379-389, 2011.

[163] C. L. Dent, Q. Ma, S. Dastrala et al., "Plasma neutrophil gelatinase-associated lipocalin predicts acute kidney injury, morbidity and mortality after pediatric cardiac surgery: a prospective uncontrolled cohort study," Critical Care, vol. 11, no. 6, article R127, 2007.

[164] J. L. Koyner, A. X. Garg, S. G. Coca et al., "Biomarkers predict progression of acute kidney injury after cardiac surgery," Journal of the American Society of Nephrology, vol. 23, no. 5, pp. 905-914, 2012.

[165] N. Srisawat, R. Murugan, M. Lee et al., "Plasma neutrophil gelatinase-associated lipocalin predicts recovery from acute kidney injury following community-acquired pneumonia," Kidney International, vol. 80, no. 5, pp. 545-552, 2011.

[166] N. Srisawat, X. Wen, M. Lee et al., "Urinary biomarkers and renal recovery in critically ill patients with renal support," Clinical Journal of the American Society of Nephrology, vol. 6, no. 8, pp. 1815-1823, 2011.

[167] A. S. Maisel, C. Mueller, R. Fitzgerald et al., "Prognostic utility of plasma neutrophil gelatinase-associated lipocalin in patients 
with acute heart failure: the NGAL EvaLuation Along with Btype NaTriuretic Peptide in acutely decompensated heart failure (GALLANT) trial," European Journal of Heart Failure, vol. 13, no. 8, pp. 846-851, 2011.

[168] V. R. Dharnidharka, C. Kwon, and G. Stevens, "Serum cystatin C is superior to serum creatinine as a marker of kidney function: a meta-analysis," American Journal of Kidney Diseases, vol. 40, no. 2, pp. 221-226, 2002.

[169] J. Mishra, C. Dent, R. Tarabishi et al., "Neutrophil gelatinaseassociated lipocalin (NGAL) as a biomarker for acute renal injury after cardiac surgery," The Lancet, vol. 365, no. 9466, pp. 1231-1238, 2005.

[170] M. Haase, R. Bellomo, P. Devarajan et al., "Novel biomarkers early predict the severity of acute kidney injury after cardiac surgery in adults," The Annals of Thoracic Surgery, vol. 88, no. 1, pp. 124-130, 2009.

[171] A. Ristikankare, R. Pöyhiä, A. Kuitunen et al., "Serum cystatin C in elderly cardiac surgery patients," Annals of Thoracic Surgery, vol. 89, no. 3, pp. 689-694, 2010.

[172] M. C. Perianayagam, V. F. Seabra, H. Tighiouart, O. Liangos, and B. L. Jaber, "Serum cystatin $\mathrm{C}$ for prediction of dialysis requirement or death in acute kidney injury: a comparative study," American Journal of Kidney Diseases, vol. 54, no. 6, pp. 1025-1033, 2009.

[173] Y. Tu, H. Wang, R. Sun et al., "Urinary netrin-1 and KIM-1 as early biomarkers for septic acute kidney injury," Renal Failure, vol. 36, no. 10, pp. 1559-1563, 2014.

[174] C. R. Parikh, H. Thiessen-Philbrook, A. X. Garg et al., "Performance of kidney injury molecule-1 and liver fatty acid-binding protein and combined biomarkers of aki after cardiac surgery," Clinical Journal of the American Society of Nephrology, vol. 8, no. 7, pp. 1079-1088, 2013.

[175] S. K. Parr, A. J. Clark, A. Bian et al., "Urinary L-FABP predicts poor outcomes in critically ill patients with early acute kidney injury," Kidney International, vol. 87, no. 3, pp. 640-648, 2015.

[176] J. M. Arthur, E. G. Hill, J. L. Alge et al., "Evaluation of 32 urine biomarkers to predict the progression of acute kidney injury after cardiac surgery," Kidney International, vol. 85, no. 2, pp. 431-438, 2014.

[177] K. Kashani, A. Al-Khafaji, T. Ardiles et al., "Discovery and validation of cell cycle arrest biomarkers in human acute kidney injury," Critical Care, vol. 17, no. 1, article R25, 2013.

[178] E. A. Hoste, P. A. McCullough, K. Kashani et al., "Derivation and validation of cutoffs for clinical use of cell cycle arrest biomarkers," Nephrology, Dialysis, Transplantation, vol. 29, no. 11, pp. 2054-2061, 2014.

[179] A. Bihorac, L. S. Chawla, A. D. Shaw et al., "Validation of cellcycle arrest biomarkers for acute kidney injury using clinical adjudication," American Journal of Respiratory and Critical Care Medicine, vol. 189, no. 8, pp. 932-939, 2014.

[180] M. Haase, J. A. Kellum, and C. Ronco, "Subclinical AKIan emerging syndrome with important consequences," Nature Reviews Nephrology, vol. 8, no. 12, pp. 735-739, 2012.

[181] S. M. Bagshaw, "Subclinical acute kidney injury: a novel biomarker-defined syndrome," Critical Care and Resuscitation, vol. 13, no. 3, pp. 201-203, 2011.

[182] C. Ronco, J. A. Kellum, and M. Haase, "Subclinical AKI is still AKI," Critical Care, vol. 16, no. 3, article 313, 2012.

[183] S. M. Bagshaw, M. Zappitelli, and L. S. Chawla, "Novel biomarkers of AKI: the challenges of progress 'amid the noise and the haste"' Nephrology Dialysis Transplantation, vol. 28, no. 2, pp. 235-238, 2013.
[184] K. Shekar, Y. L. Fung, S. Diab et al., "Development of simulated and ovine models of extracorporeal life support to improve understanding of circuit-host interactions," Critical Care and Resuscitation, vol. 14, no. 2, pp. 105-111, 2012.

[185] G. W. MacHiedo, S. B. Zaets, T. L. Berezina et al., "Traumahemorrhagic shock-induced red blood cell damage leads to decreased microcirculatory blood flow," Critical Care Medicine, vol. 37, no. 3, pp. 1000-1010, 2009.

[186] A. L. Linton, J. F. Walker, R. M. Lindsay, and W. J. Sibbald, “Acute renal failure and tubular damage due to sepsis in an animal model," Proceedings of the European Dialysis and Transplant Association-European Renal Association, vol. 21, pp. 837-842, 1985.

[187] S. Chemonges, K. Shekar, J.-P. Tung et al., "Optimal management of the critically ill: anaesthesia, monitoring, data capture, and point-of-care technological practices in ovine models of critical care," BioMed Research International, vol. 2014, Article ID 468309, 17 pages, 2014.

[188] J.-P. Tung, J. F. Fraser, M. Nataatmadja et al., "Age of blood and recipient factors determine the severity of transfusion-related acute lung injury (TRALI)," Critical Care, vol. 16, no. 1, article R19, 2012.

[189] J. P. Tung, Y. L. Fung, M. Nataatmadja et al., "A novel in vivo ovine model of transfusion-related acute lung injury (TRALI)," Vox Sanguinis, vol. 100, no. 2, pp. 219-230, 2011.

[190] M. Passmore, M. Nataatmadja, and J. F. Fraser, "Selection of reference genes for normalisation of real-time RT-PCR in brainstem death injury in Ovis aries," BMC Molecular Biology, vol. 10, article 72, 2009. 


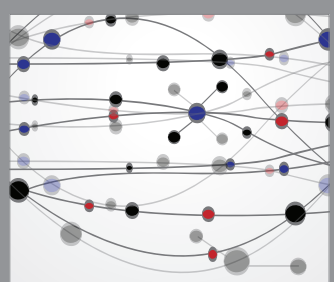

The Scientific World Journal
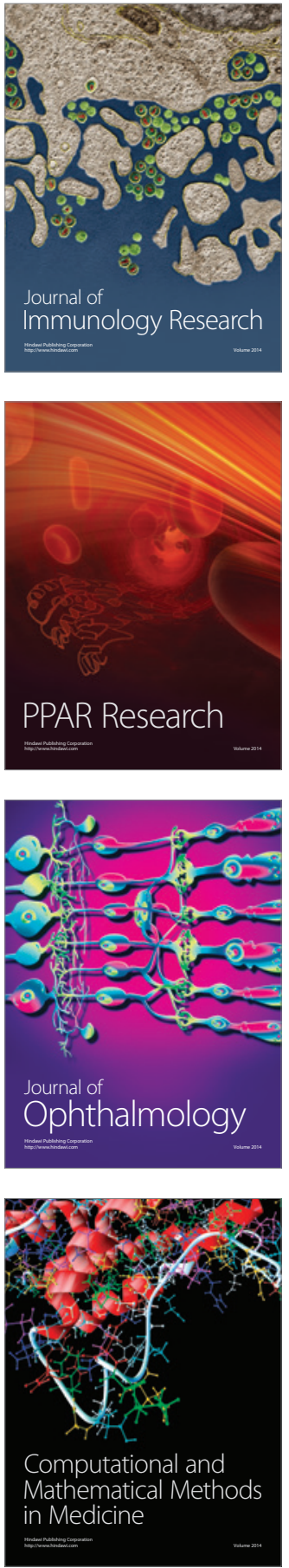

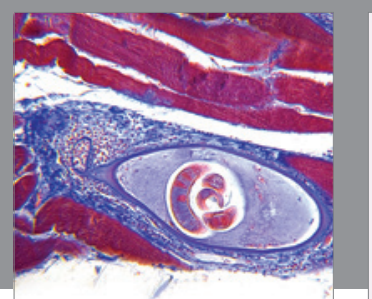

Gastroenterology Research and Practice

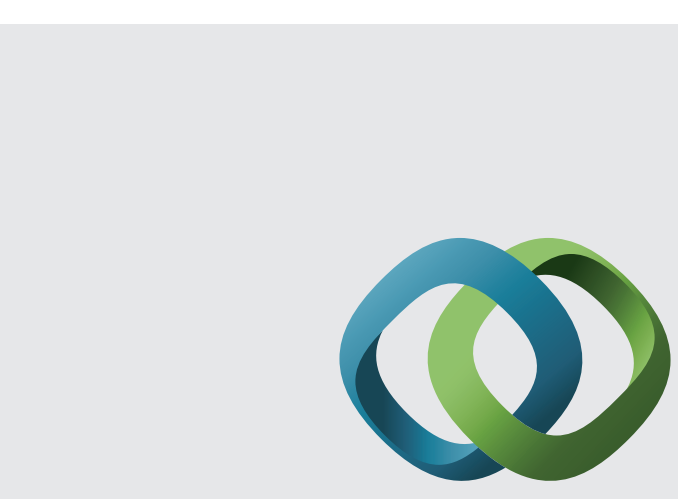

\section{Hindawi}

Submit your manuscripts at

http://www.hindawi.com
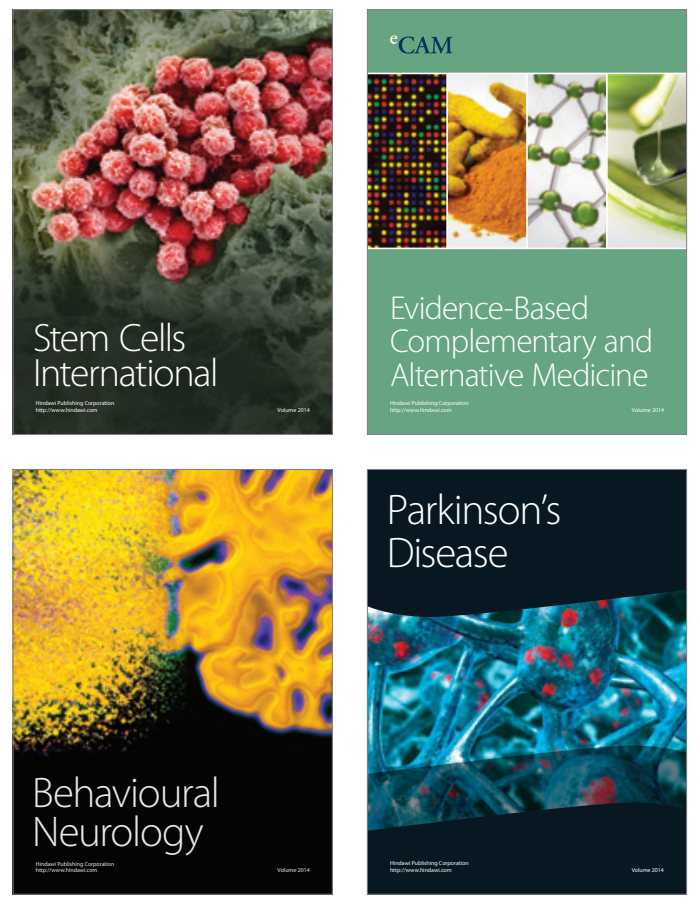
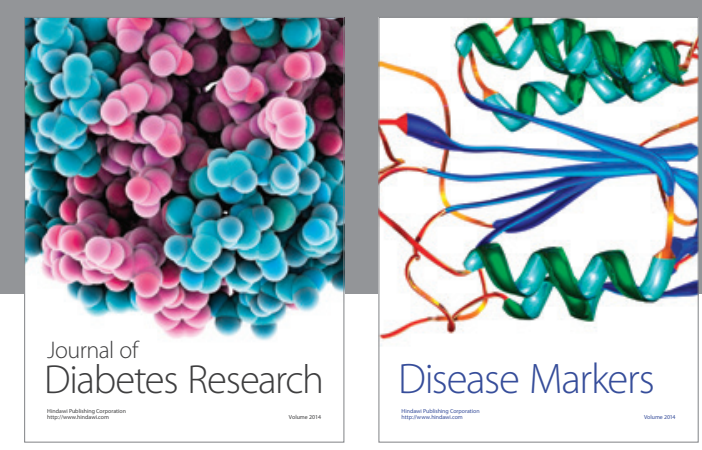

Disease Markers
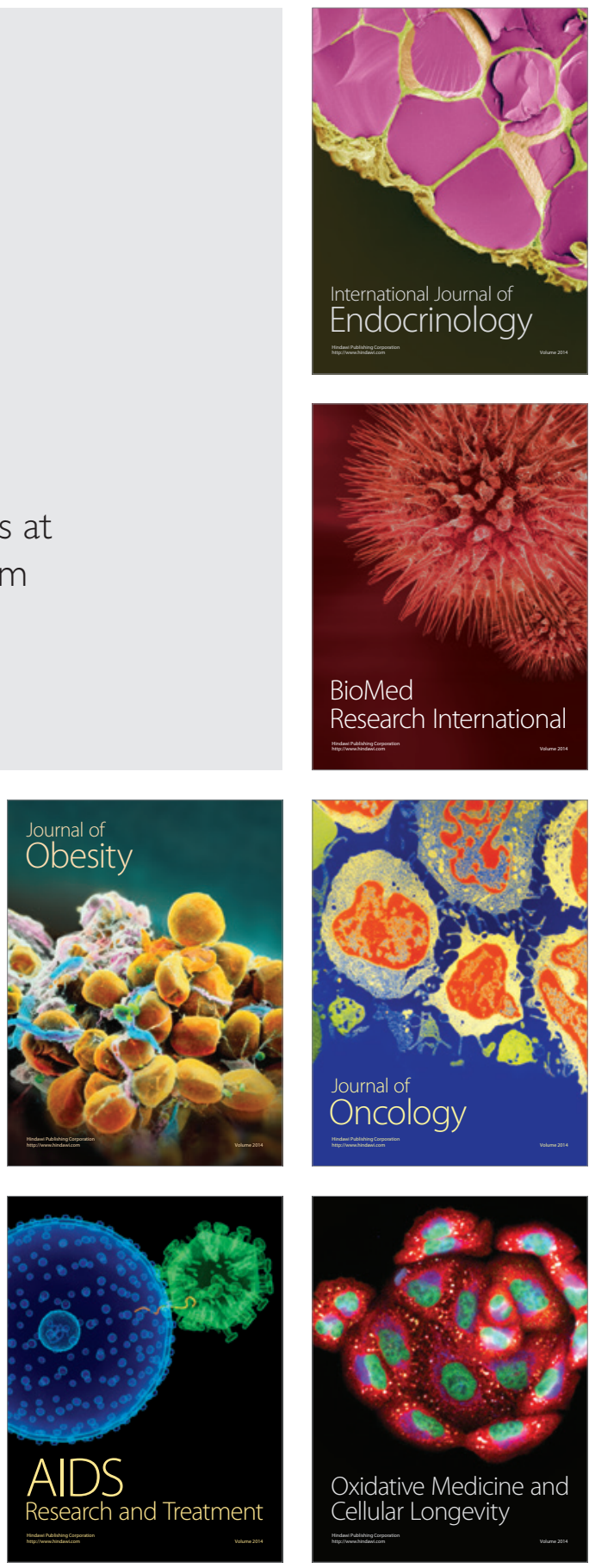